\title{
RELAÇÕES SUL-SUL EM EDUCAÇÃO: O PROGRAMA ; YO, SÍ PUEDO! E A COOPERAÇÃO EM EDUCAÇÃO DO BRICS EM FOCO
}

\author{
RELACIONES SUR-SUR EN EDUCACIÓN: EL PROGRAMA ;YO, SÍ PUEDO! Y LA \\ COOPERACIÓN EN EDUCACIÓN DEL BRICS EN CUESTIÓN
}

\author{
SOUTH-SOUTH RELATIONS IN EDUCATION: THE PROGRAM ;YO, SÍ PUEDO! \\ AND BRICS EDUCATION COOPERATION IN FOCUS
}

\author{
Thomas MUHR ${ }^{1}$ \\ Mário Luiz Neves de AZEVEDO
}

RESUMO: Este artigo adota uma abordagem histórica e global a respeito da cooperação SulSul em educação e desenvolvimento, um tema ainda pouco investigado pela academia. A primeira seção discute os conceitos de "Sul", "Sul Global" e "Cooperação Sul-Sul", contraposta às práticas de "colaboração triangular" e "transferência de melhores práticas". Com base nisso, uma revisão da literatura sobre cooperação em educação Sul-Sul distingue uma abordagem dominante incorporada nas teorias liberais e (neo)realistas de relações internacionais de uma abordagem de teoria crítica associada ao pensamento de contradependência. Enquadrado por essas discussões, este artigo apresenta dois estudos de caso das relações contemporâneas globais de educação Sul-Sul: o ;Yo, Sí Puedo! - uma campanha de alfabetização global promovida pelos governos de Cuba e Venezuela - e a agenda comum de cooperação da educação do BRICS. Embora não se possa concluir inequivocamente que a cooperação educacional Sul-Sul produza uma contra-estrutura para a governança global neoliberal da educação, o artigo mostra igualmente que os princípios Sul-Sul de solidariedade, benefícios mútuos e autoconfiança são muito praticados entre os países parceiros do Sul. Por fim, são apresentadas propostas de pesquisas futuras nesse campo.

PALAVRAS-CHAVE: Cooperação Sul-Sul. Educação. Sul Global. BRICS. ¡Yo, Sí Puedo!.

RESUMEN: El artículo adopta un abordaje histórico y global respecto a la cooperación Sur-Sur en educación y desarrollo, un tema todavía poco investigado por la academia. La primera sección discute los conceptos del "Sur", "Sur Global” y "Cooperación Sur-Sur", contrapuesta a las prácticas de "colaboración triangular" y "trasferencia de mejores prácticas". Con base en eso, una revisión de literatura sobre la cooperación en educación Sur-Sur distingue un abordaje dominante incorporado en las teorías liberales $y$ (neo)liberales de relaciones internacionales de un abordaje de teoría crítica asociado al pensamiento en contra-dependencia. Encuadrado por estas discusiones globales de educación Sur-Sur: el ;Yo, Sí Puedo! - campaña de alfabetización global promocionada por

${ }^{1}$ University of Nottingham - Centre for International Education Research (CIER), Reino Unido. Integrated Researcher - Centro de Estudos Internacionais, Instituto Universitário de Lisboa (ISCTE-IUL). ORCID: <http://orcid.org/0000-0002-8130-0405>. E-mail: t.muhr2@gmail.com

2 Universidade Estadual de Maringá (UEM), Maringá - PR - Brasil. Professor titular. ORCID: <http://orcid.org/0000-0003-0563-5817>.E-mail: mlnazevedo@uem.br 
los gobiernos de Cuba y Venezuela - y la agenda común de cooperación de la educación de BRICS. Aunque no se pueda concluir que inequívocamente que la cooperación educacional Sur-Sur produzca una contra-estructura para la gobernanza global y neoliberal de la educación, el artículo muestra igualmente que los principios Sur-Sur de solidaridad, beneficios mutuos y autoconfianza son muy practicados entre los países asociados del Sur. Finalmente, se presentan propuestas de investigación futuras para en este campo.

PALABRAS CLAVE: Cooperación Sur-Sur. Educación. Sur Global. BRICS. ¡Yo, Sí Puedo!

ABSTRACT: This paper adopts an historical and global approach to the under-researched field of South-South cooperation in education and development. The first section discusses the concepts of "the South", "the global South" and "South-South cooperation", counter-posed with practices of "triangular collaboration" and "best practice transfer". On this basis, a review of existing South-South education cooperation literatures distinguishes a mainstream approach embedded in liberal and (neo)realist international relations theories from a critical theory approach associated with counter-dependency thinking. Framed by these discussions, two case studies of contemporary global South-South education relations are presented: the ¡Yo, Sí Puedo! (Sure, I Can!) global literacy campaign promoted by the governments of Cuba and Venezuela; and the BRICS common education cooperation agenda. While it cannot unambiguously be concluded that South-South education cooperation produces a counterstructure to the neoliberal global governance of education, the paper equally shows that the South-South principles of solidarity, mutual benefits and self-reliance are very much practiced among South partners. Finally, proposals for future research in this field are presented.

KEYWORDS: South-south cooperation. Education. Global south. BRICS. ¡Yo, Sí Puedo!

\section{Introdução}

Embora o interesse acadêmico na cooperação Sul-Sul tenha crescido substancialmente na última década, as relações Sul-Sul em educação têm recebido pouca atenção da cooperação acadêmica Sul-Sul (em especial, na anglofonia), na área de desenvolvimento internacional e em estudos internacionais de educação comparada. A respeito deste tópico (Relações Sul-Sul em Educação), este artigo adota uma abordagem histórica e global, em um esforço de contribuir para preencher esta lacuna de pesquisa.

O texto se desdobra da seguinte forma: a primeira seção apresenta os conceitos de "Sul” e "Cooperação Sul-Sul”, contrapostos a práticas de "colaboração triangular" e "transferência de melhores práticas". Neste sentido, a seção dois conduz uma revisão crítica das literaturas Sul-Sul existentes de cooperação educacional. Baseando-se nestas discussões, são apresentados dois estudos de caso de relações educacionais Sul-Sul contemporâneas: o primeiro, ¡Yo, Sí Puedo! (Sim, Eu Posso!), promovido pelos governos da República de Cuba 
e da República Bolivariana da Venezuela; e, segundo, a agenda de cooperação educacional dos chamados BRICS ${ }^{3}$. Ao fim, nas conclusões do artigo, procura-se sumarizar a questão se a cooperação educacional Sul-Sul representa simplesmente a "transferência de melhores práticas" ou, alternativamente, promove-se a solidariedade a partir do Sul para a transformação global, ao mesmo tempo em que se desenvolvem propostas para uma futura agenda de pesquisa.

\section{Apresentação e esclarecimentos conceituais}

Duas conceitualizações complementares de "Sul" são relevantes para este artigo. Em termos de análises centradas no Estado-Nação, o "Sul” é um grupo de países em desenvolvimento, uma das partes do sistema geográfico binário Norte-Sul, como retratado no conhecido "Brandt Report" de $1980^{4}$. Mais recentemente, o "Sul global" também está associado à ideia de que existe uma "relação de desigualdade" não só entre os Estados, mas também entre os atores e forças sociais dentro dos países (CHISHOLM, 2009, p. 3; LECHINI, 2012). Evocando a noção de Manuel Castell de "Quarto Mundo" (CASTELLS, 2000), "Sul Global” envolve temas relacionados às desigualdades sócio-geográficas, por intermédio das quais uma identidade política transnacional coletiva pode ser produzida em razão de experiências partilhadas de exclusão, marginalização, exploração e privação de direitos (ANGOSTO-FERRÁNDEZ, 2014). O’ Sul” implica, portanto, coexistência de assimetrias de poder intra, inter e transnacionais e uma simultânea "possibilidade de solidariedade" por meio de forças políticas e sociais que resistem e procuram transformar essas desigualdades (WERNER, 2012) ${ }^{5}$.

\footnotetext{
${ }^{3}$ A sigla "BRIC" para o Brasil, Rússia, Índia e China apareceu pela primeira vez em um artigo de Jim O'Neill, da consultoria Goldman Sachs (2001), em que procurava potenciais mercados alternativos de investimento. Assim, agrupou esses países com base em projeções demográficas, modelos de capital acumulado, análise do crescimento da produção e tamanho do PIB. A primeira reunião formal dos quatro países através de seus ministros das Relações Exteriores foi realizada em setembro de 2006. Em 2010, a África do Sul se uniu para formar o "BRICS".

4 "Brandt Report" é o relatório, de 1980, escrito pela Comissão Independente, presidido pelo chanceler alemão Willy Brandt. O Relatório Brandt indica a existência de um abismo no padrão de vida entre o os hemisférios Norte e Sul.

${ }^{5}$ Com a globalização, a geografia humana e as literaturas de governança global, a expressão "internacional" denota relações oficiais entre governos nacionais ou relações inter-nações-estados; enquanto o termo "transnacional" refere-se a forças, instituições e processos que trespassam fronteiras, isto é, relações que atravessam ou perpassam fronteiras e territórios. Uma corporação transnacional "é uma empresa que tem o poder de coordenar e controlar operações em mais de um país, para além do país em que esteja sua sede" (Dicken, 2011: 110).
} 
Nesta época em que grande parte da literatura contemporânea trata sobre "Cooperação Sul-Sul" e "Cooperação Triangular" (frequentemente com referência ao Acordo de Parceria de Busan de 2011, que surgiu a partir do Quarto Fórum de Alto Nível sobre Eficácia da Ajuda, Busan, Coreia do Sul), é crucial para o rigor analítico estabelecer a diferença entre ambos, "Cooperação Sul-Sul" e "Colaboração triangular". Baseada na Teoria da Dependência, a cooperação Sul-Sul referencia-se nas ideias apresentadas após a Segunda Guerra Mundial - aproximadamente entre 1947 e 1981 - de emancipação, descolonização e autossuficiência coletiva do Terceiro Mundo para a transformação estrutural em direção a uma maior independência política e econômica frente aos países capitalistas centrais (CHATURVEDI, 2012; GOSOVIC, 2016). Os princípios de "solidariedade", “complementação" e "cooperação", estabelecidos como tal na Carta de Argel de 1967 (G-77), estão associados aos princípios de "relações iguais e recíprocas com outros países em desenvolvimento", "Não-Interferência" (ou seja, respeito à soberania) e sem exigências de “condicionalidade política” (UNESCO, 2014, p. 49).

Assim definida, a cooperação Sul-Sul exclui membros do CAD-OCDE (Comitê de Ajuda ao Desenvolvimento da Organização para a Cooperação e Desenvolvimento Eco) e procura estabelecer parcerias entre os membros do Grupo dos 77 (G-77 + China) e o Movimento dos Países Não Alinhados. Posteriormente, neste capítulo, serão tratadas as relações de educação Sul-Sul, que são consideradas como políticas de Estado (financiadas e reguladas pelo Estado), especialmente o caso de ¡Yo, Sí Puedo!, ressaltando que outras atividades (provisão, propriedade) podem ser desempenhadas por atores e forças não-estatais sociais e políticos coletivos, fora da lógica da maximização do lucro perseguida pelas corporações privadas transnacionais de educação ${ }^{6}$. Isto está, amplamente, de acordo com a distinção de dois modelos de governança da educação, uma relacionada à "transnacionalização" neoliberal em benefício das corporações transnacionais, incluindo o estabelecimento de filiais universitárias do Norte no Sul e a venda de educação on-line e licenças acadêmicas. A outra, que pode ser chamada de "cooperação horizontal" e de "internacionalização", ou seja, relações internacionais que "respeitam as idiossincrasias e identidades dos países participantes" (TÜNNERMANN-BERNHEIM, 2009, p. 51-52). Como demonstra Azevedo (2015a, b) em relação ao Brasil, ao notar que duas estratégias, de "mercantilização" e de "solidariedade" (AZEVEDO, 2015b, p. 26) podem coexistir nas

${ }^{6}$ Partindo da noção de quatro conjuntos específicos de atividades na governança da educação: financiamento; regulação (controle); provisão; propriedade (Dale, 2005). 
políticas nacionais de educação. Aliás, é importante ressaltar que grande parte da literatura a respeito de educação internacional e comparada, quando fala em "internacionalização", na realidade deveria classificar como "transnacionalização".

A cooperação Sul-Sul como emancipação do Terceiro Mundo é distinta da cooperação Sul-Sul como "colaboração triangular", na qual agências internacionais e governos do Norte atuam como "intermediários" para a "transferência de melhores práticas" entre os países em desenvolvimento no contexto da neoliberalização (SÁ E SILVA, 2009). Uma definição autorizada e qualificada de "transferência de melhores práticas", ou "transferência de políticas", considera isso como um "processo pelo qual o conhecimento sobre políticas, arranjos administrativos, instituições e ideias em um sistema político (passado ou presente) é usado no desenvolvimento de políticas, arranjos administrativos, instituições e ideias em outro sistema político" (DOLOWITZ; MARSH, 2000, p. 5).

Duas críticas fundamentais a essa prática são fundamentais para a discussão das relações de educação Sul-Sul neste artigo. Em primeiro lugar, a "transferência" pode ser de natureza mais ou menos coercitiva, desde o voluntário "desenho de lições" até a imposição direta e indireta por intermédio, entre outras formas, de pressões institucionais internacionais (OCDE, FMI, G-7, think tanks), corporações transnacionais e outros mecanismos, tais como as condicionalidades inscritas em empréstimos e subvenções (DOLOWITZ; MARSH, 2000).

Como uma relação de desigualdade em relação à autonomia do ator, o elemento coercitivo na "transferência" ressalta a diferença entre a colaboração triangular e a cooperação Sul-Sul como uma estratégia de "contra-dependência": ao contrário da "dependência" como relação de desigualdade que implica "ausência de autonomia do ator", a "dependência" denota "interdependência assimétrica" que, como relação de "controle mútuo" e "confiança", é legitimada se estabelecida de forma consensual (CAPORASO, 1978). Uma vez que a autonomia ou "total autossuficiência" parece ilusória para as nações, especialmente as pobres, a "dependência controlada" é uma relação mais igualitária, já que os parceiros podem "influenciar a natureza fundamental de suas relações", apesar das assimetrias de poder existentes nas interdependentes relações Sul-Sul (ERISMAN, 1991, p. 143). Por conseguinte, as relações de solidariedade e win-win (vantajosas para ambas as partes) associadas à cooperação Sul-Sul não devem, por si só, serem equiparadas ao altruísmo e à ausência de interesses e de assimetrias de poder. Mais que isso, enquanto que os princípios de solidariedade, complementaridade e cooperação podem implicar altruísmo, os interesses comerciais e políticos são igualmente parte das relações Sul-Sul (MUHR, 2016a). No entanto, 
isso não se traduz axiomaticamente em um mercado competitivo e em uma lógica de maximização de lucro. Por exemplo, de acordo com a situação econômica do parceiro, o internacionalismo socialista cubano, que tem sido fundamental na cooperação Sul-Sul da América Latina e do Caribe, às vezes cobra taxas comerciais (variáveis) pelos serviços, porém abaixo dos preços do mercado mundial. (ver Hickling-Hudson et al., 2012, p. 19). Portanto, é decisivo se as interdependências Sul-Sul geram a contra dependência do Sul - isto é, a independência e autoconfiança coletivas.

Ademais, a segunda grande crítica à "transferência" é a de que esse mecanismo de relações políticas internacionais despolitiza a cooperação Sul-Sul, pois é interpretada como mera tecnicalidade "não mais enraizada na mobilização política do Sul” (SÁ E SILVA, 2009, p. 51). A instrumentalização ou cooptação e reconceptualização da cooperação Sul-Sul como transferência, em vez de "processo coletivo", mina o caráter "orgânico, político e potencialmente inovador da cooperação Sul-Sul” (JULES; MORAIS DE SÁ; SILVA, 2008, p. 58).

A literatura sobre educação comparada internacional reverbera essas discussões. Com o Banco Mundial adotando o papel de um "banco de conhecimento" global na década de 1990, assumiu simultaneamente o papel de "supervisor" e "dispensador" (fonte) de "melhores práticas". Outras organizações Internacionais de governança global, incluindo Transparência Internacional e Agências das Nações Unidas (ONU), seguem o exemplo do Banco Mundial: em conjunto com as condicionalidades impostas pelos financiadores, a exemplo dos compromissos com eficiência, eficácia (performatividade), benchmarking, rankings e classificações associadas a "padrões internacionais", a transferência de melhores práticas tem sido considerada um mecanismo "unidirecional" que perpassa por "concorrência entre países, coerção e convergência" (STEINER-KHAMSI, 2007, p. 285-286; 2012). Neste sentido, a UNESCO também adotou a transferência de melhores práticas como um instrumento dentro do seu programa e estratégia de Educação para Todos (MORAIS DE SÁ; SILVA, 2009, p. 50) e, até mesmo, de documentos que fazem referência ao espírito de cooperação Sul-Sul do pós-Segunda Guerra Mundial, como o relatório BRICS: Construindo a Educação para o Futuro (UNESCO, 2014). A visão da cooperação Sul-Sul é mais um pretexto do que um processo político, afirmando que os BRICS devem "aprender uns com os outros" para a melhoria da "eficácia de seus programas de cooperação" (UNESCO, 2014, p. 3). 


\section{Revisão da Literatura}

Considerando as discussões conceituais da seção anterior, a seguinte revisão da literatura analítica limita-se às publicações acadêmicas contemporâneas que se relacionam com a cooperação Sul-Sul como uma política de intervenção do Estado e um esforço potencialmente de contra dependência solidária. Projetos e relações dentro da lógica do mercado de privatização e comoditização, como a cooperação educacional do governo turco com as repúblicas turcas (YANIK, 2004), não são compreendidas como movimentos de contra dependência solidária. Como tal, a revisão serve para definir o contexto para os estudos de caso a seguir e não há pretensões de um trabalho em completude final. Aparentemente, o único livro acadêmico, em inglês, que sinaliza em seu título a existência de um campo de cooperação educacional e para o desenvolvimento Sul-Sul é South-South Cooperation in Education and Development, de Linda Chisholm e Gita Steiner-Khamsi (CHISHOLM; STEINER-KHAMSI, 2009).

Embora levantando questões importantes sobre definições de "Sul" e práticas de transferência de políticas, os estudos de casos reunidos transcendem as iniciativas de colaboração triangular e as que envolvem membros do CAD da OCDE (como o Japão), corporações transnacionais e atores privados e de ONGs (ver também Heyneman, 2010). Ao se analisar a literatura acerca das relações educacionais Sul-Sul, sem necessariamente torná-la explícitas, podem ser discernidos dois grandes campos: uma abordagem mainstream, inserida nas teorias das relações internacionais liberais e (neo)realistas, e uma abordagem de teoria crítica, associada ao pensamento de contra dependência. Adiante, ambas são apresentadas. De modo geral, a literatura predominante baseia-se em uma abordagem metodologicamente nacionalista (de "país") como base de comparação (por exemplo, Robertson \& Dale, 2008), frequentemente com fundamentação liberal e (neo)realista, de competição entre estados-nação e de conquista de soft power (em que os Estados são vistos como sujeitos que têm a habilidade influenciar outros estados para "obter resultados preferenciais por cooptação e atração" (NYE, 2010, p. 216).

Grande parte desta literatura concentra-se na temática educação superior no grupo de países BRIC ou BRICS e em temáticas originárias de seus membros individuais, especialmente China e Brasil. Um olhar mais atento revela, contudo, que as principais publicações nesta área são simplesmente coleções de estudos de países individuais sem explorar relações, agendas e sinergias geradas entre atores do Sul. Por exemplo, Carnoy et al. comparam, em BRIC state behavior (2013, p. 26), a elaboração de políticas nacionais de 
educação superior, "desenvolvendo uma ampla visão dos sistemas de educação superior em cada país" (2013, p. 4). Altbach et al estabelecem comparações entre "os sistemas acadêmicos e os desafios de cada um dos países do BRIC", apontando para "estratégias internacionais agressivas" de cada um desses "países" para "competir uns com outros por prestígio e posicionamento nos rankings globais" (ALTBACH et al., 2013, p. viii-ix). Da mesma forma, Pillay e seus colegas, em variados capítulos de compilação "comparativa", restringem-se a "perspectivas nacionais" das "políticas que estão sendo implementadas pelos governos dos BRICS” Pillay et al. (2015, p. 5-6). Já a coletânea especial, organizada por Oleksiyenko e Yang, comporta uma "comparação" entre as políticas de internacionalização dos sistemas de educação superior dos membros do BRICS, referindo-se principalmente às iniciativas de cooperação transnacional, neoliberal e "Norte-orientada", bem como àquelas apoiadas em soft power (2015, p. 3).

Inerentemente eurocêntrica, esta literatura toma por referência os padrões globais estabelecidos de ranking e benchmarking, como também os sistemas de educação superior do Norte para comparação. A exemplo de Carnoy et al, que insistem que "os países BRIC provavelmente terão que fazer alguns investimentos importantes para conduzir seus sistemas de educação superior em linha com os modelos de universidades norte-americanas e europeias" (2013, p. 14). Da mesma forma, Lane \& Kinser estabelecem comparações de formas "não-públicas" (não-estatais) de educação superior transfronteiriça e reconhecem o domínio dos governos e ONGs ocidentais na formatação de políticas de educação superior em países africanos. Eles também percebem que os governos da Índia, China e Brasil, ao estabelecerem acordos de cooperação com governos africanos neste sector, são conduzidos por valores baseados na "competitividade econômica e em soft power" (2013, p. 106-107, 119). Com referência às duas contribuições, presentes na coletânea organizadas por Cheng e Chan, são envolvidos alguns aspectos de cooperação Sul-Sul na educação (China, Capítulo 8; Índia, Capítulo 10). Os autores, Cheng e Chan, concluem que "a China e a Índia têm a intenção de ajudar a intervenção na educação como um poder suave (soft power) para reidentificarem-se como centros educativos e líderes regionais que exercem maior influência sobre a Ásia em desenvolvimento" (2015, p. 246).

Jules e Morais de Sá e Silva (2008) destacam em sua revisão de diferentes abordagens disciplinares de cooperação e transferência Sul-Sul, segundo uma visão (neo)realista de estado-nação como unidade homogênea, racionalmente comportada e de dominação ("política de poder", por exemplo, BUZAN et al., 1998), que "a cooperação real é 
improvável” (JULES; MORAIS DE SÁ; SILVA, 2008, p. 53). De acordo com esta abordagem, a cooperação Sul-Sul é um instrumento do Estado para perseguir seus interesses e, neste sentido, o "poder suave" descreve o poder como um mecanismo unidirecional (em vez de dialético-relacional) no qual o afetado é inerentemente objetivado. Como diz King em seu China's Aid \& Soft Power in Africa, soft power significa uma relação "vencedorperdedor" que exclui a essência da cooperação Sul-Sul, ou seja, de interesses comuns ou mútuos, como o objetivo de autossuficiência, solidariedade, igualdade, cooperação para benefício de ambos (win-win) e benefício mútuo (KING, 2013, p. 10-11, 193-194). Provavelmente a análise mais completa disponível sobre as relações de educação Sul-Sul foi realizada por King, depois de seis anos de investigação "safari” (2013, p. 208), de 2006 e 2012, em que realiza uma crítica histórica fundamentada em uma metodologia de comparação crítica das "diferenças e semelhanças da cooperação chinesa com a cooperação tradicional [OECD-DAC] a partir de doadores" (2013, p. x), distintamente da "perspectiva da China sobre a cooperação" em educação e formação (a que o governo chinês refere-se como “desenvolvimento de recursos humanos") (2013, p. ix).

Isso permite identificar a "aprendizagem de políticas" como aprendizagem mútua ou bidirecional, em vez de "transferência de políticas". Enquanto King detecta contradições no mais recente discurso de cooperação oficial Sul-Sul da China e propõe um ambíguo "soft soft power" ou "soft power com características chinesas", o livro como um todo refuta a transferência da noção de "soft power" do discurso da política externa dos EUA para a prática de cooperação da China. Ainda menos dúvida sobre isso marca o relato histórico de Niu e Liu (2016) sobre as relações de educação entre a China e a África, fundamentadas na filosofia confucionista de paz e harmonia, amizade e benefício mútuo.

Outros trabalhos críticos em educação adotam uma abordagem mais explícita de contra dependência. A pesquisa de Hickling-Hudson sobre a educação na Revolução Cubana, que evoluiu para um volume editado que ilumina de modo abrangente a multidimensionalidade do "internacionalismo cubano integrando solidariedade e cooperação Sul-Sul" na educação "baseado não em normas de mercado (lucros e competição)" (HICKLING-HUDSON et al., 2012, p. 4-5) - em países parceiros como a Bolívia, a Jamaica, o Gana, a Namíbia, Timor-Leste e a Venezuela.

Da mesma forma, a etnografia multiétnica de Fiddian-Qasmiyeh, conduzida desde 2001 na Argélia, Cuba, Líbano, Líbia e Síria, observa claramente o internacionalismo da educação socialista na forma em que Estado cubano e líbio oferecem ensino primário, 
secundário e terciário fornecido gratuitamente para refugiados saharauis e palestinos nas regiões do Médio Oriente e Norte da África. Uma análise relacional das mobilidades dos estudantes-refugiados desagrega as complexidades "transregionais, intergeracionais e multidirecionais" (FIDDIAN-QASMIYEH, 2015, p. 6) desses programas de educação, ao mesmo tempo em que identifica resultados contraditórios em relação à autossuficiência e à dependência da ajuda do Norte.

Finalmente, existe um conjunto de trabalhos críticos que abordam a cooperação SulSul por intermédio de lentes da integração regional (regionalismos) e da governança multiescalar. Isso inclui: privatização e descomoditização da educação e maior equidade no acesso à educação em/através da Aliança Bolivariana para os Povos da Nossa América - Acordo Comercial do Povo (ALBA-TCP) e o Mercado Comum do Sul (MERCOSUL ) (MUHR, 2010, 2016b); e, como expressão da aberta luta de classes na América Latina e Caribe, contestando projetos políticos de governança da educação superior no MERCOSUL (AZEVEDO, 2014; PERROTTA, 2016).

\section{Estudos de caso de relações Sul-Sul em educação}

Com base na revisão da literatura anterior, os dois estudos de caso que seguem, ;Yo, Sí Puedo! (campanha de alfabetização global) e a agenda de educação BRICS, procuram sublinhar a relevância da educação como uma dimensão indispensável na cooperação Sul-Sul como um "projeto político de emancipação, libertação, independência política e econômica" e “processo de mudança de sistema" (GOSOVIC, 2016, p. 733, 740). Provavelmente, esse objetivo requer uma abordagem holística da educação que inclua modalidades formais e não formais em todos os níveis do processo educacional. Assim, os dois estudos de caso procuram ampliar o foco reducionista que domina a literatura existente sobre as relações Sul-Sul em Educação Superior.

\section{¡Yo, Sí Puedo!: Cooperação Sul-Sul Global ${ }^{7}$}

¡Yo, Sí Puedo! foi desenvolvido a partir do início dos anos 2000 por Leonela Relys Díaz no Instituto Pedagógico Latino-Americano e Caribenho (IPLAC), subordinado ao Ministério da Educação cubano. Embora ;Yo, Sí Puedo! é frequentemente usado como se

${ }^{7}$ Esta seção é baseada em Muhr (2015). Sugere-se ao leitor interessado, fazer a leitura deste artigo para uma visão mais acurada sobre o argumento aqui desenvolvido. 
fosse sinônimo de campanhas ou programas de alfabetização associados; em termos estritos, o nome denomina um método alfanumérico que faz uso da tecnologia audiovisual. $\mathrm{O}$ foco aqui, no entanto, não é o próprio método nem suas conquistas quantitativas ${ }^{8}$. Em vez disso, esta seção contesta a associação da globalização de ;Yo, Sí Puedo! como "transferência" (Steele 2009: 36), "transferência de políticas" ou "transferência de melhores práticas" e referência à "autonomia do Terceiro Mundo", simplesmente, como sendo "parte do discurso" (JULES; SÁ; SILVA, 2008, p. 57; SÁ; SILVA 2009, p. 52-55).

A globalização de ;Yo, Sí Puedo! tem origem na solidariedade Sul-Sul da Revolução Cubana em educação. Vale lembrar que, historicamente, o "internacionalismo" cubano sempre envolveu as relações inter-estados, bem como o apoio transnacional aos movimentos revolucionários (DOMÍNGUEZ, 1989; HICKLING-HUDSON et al., 2012).

Nesse sentido, ;Yo, Sí Puedo! tem se globalizado por intermédio da cooperação intergovernamental Sul-Sul, especialmente entre os onze estados membros da ALBA-TCP, fundada como um regionalismo de cooperação Sul-Sul pela República de Cuba e a República Bolivariana da Venezuela em 2004. De fato, a primeira internacionalização do método ocorreu na forma da campanha nacional de alfabetização do governo venezuelano Misión Robinson, lançada em $1^{\circ}$ de julho de 2003. Também com o apoio venezuelano, ¡Yo, Sí Puedo! foi implantado em pelo menos 27 países da América Latina e Caribe por governos e atores sociais não estatais (como o Movimento dos Trabalhadores Rurais Sem Terra do Brasil MST), bem como na África (Angola, Cabo Verde, Guiné Bissau, Etiópia, Moçambique, Namíbia, Nigéria, África do Sul), Ásia (especialmente Timor Leste) e na Austrália, Canadá, Nova Zelândia, Espanha e EUA. Na maioria - se não em todos - destes casos, a cooperação foi solicitada por forças e atores políticos e sociais globais do Sul - grupos e associações baseados na comunidade e nos movimentos (em vez de ONGs e setores empresariais com fins lucrativos), partidos políticos e entidades políticas subnacionais, como os governos municipais. Assim, a globalização de ;Yo, Sí Puedo! é um processo orientado pela demanda, puramente voluntário e isento de condicionalidades, pelo qual a cooperação solidária cubana normalmente inclui assessores e logística (televisores, reprodutores de vídeos, materiais didáticos, em alguns casos painéis solares para geração de energia em zonas remotas, testes de

${ }^{8}$ Para aspectos pedagógicos, ver Boughton \& Durnan (2014). Pelo uso de ;Yo, Sí Puedo!, Antígua e Barbuda, o Estado Plurinacional da Bolívia, a República da Nicarágua e a República Bolivariana da Venezuela foram declarados territórios sem analfabetismo pela UNESCO. Enquanto números precisos do impacto global de ;Yo, Sí Puedo! Mesmo não havendo números precisos, segundo o diretor do IPLAC, César Torres Batista, no final de 2014, 8.203.324 pessoas haviam sido alfabetizadas por intermédio do ;Yo, Sí Puedo! em todo o mundo, e mais de um milhão se beneficiaram do acompanhamento ;Yo, Sí Puedo Seguir! 
visão e óculos de leitura). É importante ressaltar que são os parceiros que lideram a contextualização (assumindo a titularidade/propriedade) e implementam a campanha em suas localidades. Até 2015, o método havia sido adaptado em pelo menos 14 diferentes contextos sócio-lingüísticos, incluindo aimará, crioulo, inglês, guarani, português, quíchua, suaili, tétum e braile.

O caso da Nicarágua é ilustrativo disso, ressaltando a diferença entre o "aprendizado de lições" instrumental e o "processo coletivo" (cooperação) de aprendizagem baseado na mobilização política. Após um pedido de cooperação da Associação de Educação Popular Carlos Fonseca Amador, sediada em Manágua, em 2005, o governo cubano forneceu o método ;Yo, Sí Puedo! junto com seis assessores e recursos para 5000 chamados "pontos de alfabetização".

Nos dois anos seguintes, ¡Yo, Sí Puedo! foi implementada por intermédio de uma aliança do Estado cubano, da Associação Fonseca Amador e dos conselhos municipais da Nicarágua, em que a Associação Fonseca Amador foi responsável pela coordenação técnicopedagógica, treinamento e avaliação, enquanto os municípios participantes estabeleceram Comissões Municipais de Alfabetização. Com o retorno da Frente Sandinista de Libertação Nacional (FSLN) ao governo nacional em 2007 e com a Nicarágua unindo-se à ALBA-TCP, ¡Yo, Sí Puedo! foi universalizada como Campanha Nacional de Alfabetização "De Martí a Fidel" (lançada em 23 de junho de 2007), apoiada por 86 assessores cubanos e 61 voluntários venezuelanos. Em 2009, quando a Unesco declarou a Nicarágua como país livre de analfabetismo, 57.731 trabalhadores de alfabetização voluntária estavam mobilizados; em 2013, existiam 13.519 pontos de alfabetização, envolvendo ativamente 75.018 alunos. Mesmo que a Nicarágua, devido à trajetória histórica da nação da revolução socialista, pode não ser um exemplo representativo de todos os contextos em que ;Yo, Sí Puedo! está implantado, deve-se notar que há mais de 1,1 milhões de pessoas (de uma população total de cerca de seis milhões em 2014) mobilizadas anualmente em ações de solidariedade organizadas e coletivas (em vez de caridade individualista liberal), não apenas na campanha de alfabetização, mas também em outros estados, inclusive nos países associadas à ALBA-TCP, os atores mobilizados em torno do projeto ;Yo, Sí Puedo! promoveram ações relacionadas a reflorestamento, saúde pública e inclusão social de crianças de rua.

Mesmo que o propósito político de ;Yo, Sí Puedo! seja raramente explicitado, os estudos de caso disponíveis destacam a mobilização social e o elemento emancipatório e empoderador do método de educação popular, relacionado à conscientização da educação 
transformadora freiriana, como, por exemplo, concluem Boughton e Durnan (2014) com base no envolvimento deles em ;Yo, Sí Puedo! em Timor-Leste e na Austrália aborígene. Com base nas análises de Boughton e Durnan sobre ;Yo, Sí Puedo! em Timor-Leste e na Austrália aborígene, este programa pode ser considerado como uma "pedagogia contemporânea dos oprimidos" (BOUGHTON; DURNAN, 2014, p. 565). A "teoria da libertação" de Paulo Freire torna-se "prática libertadora" (BOUGHTON; DURNAN, 2017, p. 46) que "pode contribuir para $[. .$.$] aumentar o controle da comunidade sobre a agenda do desenvolvimento e, ao mesmo$ tempo, construir e fortalecer os elos de solidariedade entre as diferentes populações do Sul Global" (BOUGHTON; DURNAN, 2014, p. 565, 576).

Em vez de um transplante técnico unidirecional que conduz à competição e à simples convergência, ;Yo, Sí Puedo! é uma síntese do que pode ser a cooperação Sul-Sul, como um processo coletivo localmente apropriado, com o potencial de construir uma identidade política transnacional para uma transformação estrutural global rumo a uma ordem mundial socialmente justa e democrática.

\section{BRICS: rumo a uma agenda comum de cooperação em educação}

Este estudo de caso é uma primeira aproximação à agenda de educação do BRICS e pode ser visto como uma resposta à literatura já discutida sobre a questão, principalmente de duas formas principais: primeiro, metodologicamente, para superar a prática de estudos que simplesmente agrupam os países membros do BRICS sem explorar os projetos comuns, relações e potenciais sinergias dentro do BRICS como uma unidade. Segundo, desafiar o reducionismo da educação como sendo somente a educação superior na literatura acadêmica sobre os BRICS, juntamente com esses julgamentos prematuros de "agrupá-los [os países BRICs] simplesmente para fins analíticos sobre educação superior não é relevante" (ALTBACH; BASSETT, 2014, p. 2). Essa discussão setorial do estabelecimento de uma agenda de educação do BRICS desde 2015 está incorporada em uma análise do compromisso geralmente crescente com a cooperação Sul-Sul nos BRICS nos últimos anos, emoldurada pela questão de saber se a cooperação educacional BRICS pode contribuir para a construção de uma estrutura de contra dependência.

Uma análise das nove declarações de cúpula anuais do BRIC(S) e respectivos planos de ação entre 2009 e 2017 (BRIC, 2009; 2010; BRICS 2011, 2012, 2013, 2014, 2015a; 2016c; 2017b), revela uma mudança discursiva em direção à agenda de cooperação Sul-Sul 
mais assertiva ao longo do tempo. Embora seja um discurso híbrido que também integra elementos do discurso de "boas práticas", o discurso da cooperação Sul-Sul domina claramente, especialmente a partir de 2014/2015. Em primeiro lugar, enquanto a "cooperação" como um princípio de relações Sul-Sul se deslocou para o centro das discussões, de uma menção marginal no item 12 da Declaração Conjunta de 2009, a "cooperação" foi assinalada nos itens 1 e 2 nas declarações subsequentes. A Declaração Ufa de 2015 (BRICS, 2015a, itens 56, 66) refere-se abertamente às relações "cooperação SulSul"9 e "ganha-ganha" (win-win) - no entanto, estes conceitos estão ausentes nas declarações de 2016 e 2017.

Em segundo lugar, os princípios-chave da cooperação Sul-Sul entraram no discurso do BRICS após 2009 (estavam ausentes na Declaração Conjunta de 2009) - "solidariedade", desde 2010; "Mútuo" e/ou "benefícios compartilhados", desde 2011; "Complementaridade" e "sinergias", desde 2012; "Amizade" (como usado na cooperação Sul-Sul chinesa, ver King 2013), desde 2014; e "convergência", desde 2015 - e sua presença aumentou significativamente a partir de 2014/2015. Por exemplo, a "solidariedade" aumentou de nove registros, entre 2010-2014, para 13 no período 2015-2017; "Mútuo"/“benefícios compartilhados" de apenas duas menções no período 2010-2013, para 17 nas declarações de 2014-2017; e "amizade" (em relações internacionais) de uma alusão em 2014 para cinco em 2017.

Além disso, as ideias de cooperação Sul-Sul associadas, tais como "interesses comuns" (ou interesses "mútuos" ou "compartilhados") e "parceiro"/“parceria" (em vez da relação doador-receptor convencional), respectivamente, aumentaram de cinco e 14 referências nas declarações de 2009-2014 para 15 e 36 referências nas declarações de 20152017.

Terceiro, relacionado à ideia de "parceria", o princípio de "nãointerferência"/"soberania" (e suas conotações de "equidade" e "igualdade" nas relações internacionais) foram afirmadas, aumentando de um total de 12 menções durante 2009-2013, para 73 nas declarações de 2014-2017.

Em quarto lugar, a colaboração "triangular" é totalmente ausente no discurso do BRICS, que ressalta a reivindicação do BRICS como um projeto de "cooperação estratégica"

${ }^{9}$ Embora espelhando os discursos dominantes da cooperação para o desenvolvimento, "destacando que a cooperação Sul-Sul não é um substituto, mas sim um complemento à cooperação Norte-Sul, que continua sendo o principal canal da cooperação internacional para o desenvolvimento" (BRICS, 2015a, Item 66). 
e "parceria estratégica" (por exemplo, BRICS, 2017b) para "desenvolvimento comum" (BRICS, 2011; 2012; 2016c; 2017b).

Finalmente, em quinto lugar, desde 2014, o BRICS vem adotando uma abordagem holística dos direitos humanos, dando igual ênfase aos "direitos civis, políticos, econômicos, sociais e culturais, bem como ao direito ao desenvolvimento" (BRICS, 2015a, item 10). Ao se referir ao "direito ao desenvolvimento", o BRICS evoca a Declaração das Nações Unidas sobre o Direito ao Desenvolvimento, de 1986, que se refere à "ordem social e internacional", contemplando os "direitos coletivos dos povos (do Sul)". "Direitos coletivos de solidariedade vis-à-vis aos povos do Norte" (NOWAK, 2003, p. 24). Isto é, "o direito dos povos à autodeterminação" (política, econômica, social, cultural) (UNITED NATIONS, 1986), que tem sido a base da cooperação Sul-Sul desde a Conferência de Bandung de 1955 (PHUM; SHILLIAM, 2016). Assim, o apelo do BRICS pelo "direito ao desenvolvimento" pode ser entendido como uma retomada implícita da luta descolonialista do Sul pela "Nova Ordem Econômica Internacional [NOEI] das Nações Unidas baseada na igualdade soberana, interdependência, interesse mútuo e cooperação entre todos os Estados" (NAÇÕES UNIDAS, 1986, Artigo 3.3).

O hibridismo nos discursos do BRICS deriva da referência às chamadas "melhores práticas", com uma a três ocorrências em cada uma das declarações do BRICS desde 2012. Entretanto, de um total de 12 menções, dez referem-se ao "compartilhamento" e às "trocas" mútuas, que podem ser consideradas compatíveis com o princípio Sul-Sul de não imposição. As outras duas passagens referem-se a "aprender" com as "melhores práticas disponíveis" (BRICS 2012, item 44) e "explorar as possibilidades de cooperação para o desenvolvimento de habilidades através da implementação das melhores práticas internacionais" (BRICS 2015a, item 63 a respeito da educação), que novamente denotam um processo mais voluntário (aprendizagem mútua), ao invés de transferência coercitiva.

Hierarquicamente, em todos os casos, esses elementos do discurso da "melhor prática" são introduzidos somente depois que a questão principal da cooperação Sul-Sul foi estabelecida como o quadro geral de referência (sobre hierarquia e hibridismo nos estudos do discurso, ver Fairclough, 2003). De fato, a substituição de "melhores práticas" por "boas práticas" e "práticas efetivas" tanto na cúpula geral de 2017 quanto nas declarações de educação (BRICS, 2017a, b) sugere um desligamento do discurso político dominante. Em suma, o discurso do BRICS sugere fortemente uma compreensão da cooperação Sul-Sul como 
processo coletivo, em vez de meramente técnico, com elementos de maior autoconfiança (coletiva).

Materialmente, isso se traduz na construção de uma estrutura de contrapoderes para a “transformação estrutural” (BRICS, 2016c, item 26) orientada pela visão "comum” ou "compartilhada" (BRICS, 2016c, item 6; BRICS, 2017b, item 1) de uma "ordem política e econômica internacional mais justa, equitativa, justa, democrática e representativa" (BRICS, 2017b, item 2). Enquanto a industrialização (para "agregação de valor" e integração em "Cadeias Globais de Valor") é identificada como um "pilar central" nesse esforço (BRICS, 2016c, itens 26,37), de igual importância é a transformação contínua da governança global regime. A este respeito, em reação à relutância dos governos do Norte em "reformar" (ou seja, democratizar) o Banco Mundial e o FMI, isto foi mais demandado pelo BRIC(S) entre 2010 e 2012, ao lado de "uma reforma abrangente da ONU"; incluindo o seu Conselho de Segurança (BRICS, 2016c, item 10), o estabelecimento do" Novo Banco de Desenvolvimento" e o “Arranjo Contingente de Reservas entre os países do BRICS” emergiram na agenda em 2012 e estão em operação desde 2015 (BRICS 2016c, item 3; Cooper, 2017).

A mobilização política do Sul para "corrigir os desequilíbrios de desenvolvimento Norte-Sul" (BRICS, 2017b, item 6) envolve o aprofundamento da cooperação com os países em desenvolvimento não-BRICS, conhecida como "cooperação BRICS Plus" para a construção de amplas parcerias para o desenvolvimento. $\mathrm{O}$ tema "fortalece a cooperação mutuamente benéfica para o desenvolvimento comum" (BRICS, 2017b, item 69). Isso não é apenas retórica, por exemplo, Hopewell (2017) observa que o duradouro "alinhamento estratégico" fundamentado em "solidariedade" e "interesse comum", especialmente entre o Brasil, China e Índia em aliança com a grande maioria dos governos de países em desenvolvimento dentro da Organização Mundial do Comércio, produziu transformações concretas das estruturas de poder na governança do comércio global em favor do Sul. No entanto, uma posição cada vez mais declarada contra "políticas voltadas para dentro" (BRICS, 2017b, item 7) de acordo com a lógica de uma "economia mundial aberta" (BRICS, 2017b, item 3) pode minar o potencial emancipatório do modelo do BRICS, como também uma associação global de "desenvolvimento" (incluindo "desenvolvimento sustentável”, que está em alinhamento com os Objetivos de Desenvolvimento Sustentável da ONU) com crescimento econômico, reconhecendo apenas marginalmente a dialética do "econômico, social e ambiental” no "desenvolvimento sustentável” (veja BRICS , 2017b, item 14). 
Mesmo que o Novo Banco de Desenvolvimento seja uma "instituição distinta" em termos "normativos" e "instrumentais" - o primeiro referente aos princípios de "igualdade" e "benefício mútuo", e o segundo à "inovação de produto" em relação ao financiamento exclusivo projetos de energia renovável de pequena escala (em vez de em larga escala) - a redução de "desenvolvimento sustentável" para "infraestrutura verde" e "financiamento verde" (COOPER, 2017) dentro de uma lógica de crescimento não fornece um paradigma de desenvolvimento genuinamente alternativo.

Portanto, pode-se concluir que o projeto BRICS procura principalmente aumentar o “acesso e representação nas instituições e processos que definem, administram e sustentam as regras internacionais" (“contestação sobre representação”) em vez de desafiar os princípios a ordem liberal internacional liderada pelo Ocidente ("contestação normativa"), apesar de “algumas áreas de contestação normativa genuína” (NEWMAN; ZALA, 2017, p. 1, 12). Ou seja, segundo a perspectiva de relações internacionais mais ortodoxa de Newman e Zala, o BRICS demonstra uma adesão esmagadora às "normas substantivas e processuais" que regem o comércio e o desenvolvimento, a paz e a segurança, a soberania do Estado, o direito internacional e a prática diplomática e a "equidade, justiça e democracia" nas relações internacionais (NEWMAN; ZALA, 2017, p. 5-7).

No entanto, uma vez que os princípios e as práticas de cooperação Sul-Sul sejam incluídos na análise, amplamente ignorados por Newman e Zala, o projeto do BRICS, especialmente desde 2014/2015, representa um desafio normativo muito maior para a governança global do desenvolvimento do que é frequentemente assumido. Isto é sublinhado pela sugestão de que, no discurso do BRICS, "soberania nacional" relaciona-se com a resistência ao quadro normativo da assistência ao desenvolvimento liderada pelo Norte, especialmente as condicionalidades e a "agenda da eficácia da ajuda" do imperialismo ocidental em geral (ABDENUR, 2014, p. 1883)

A educação é considerada apenas duas vezes, em termos muito gerais, nas declarações de cúpula do BRIC(S) entre 2009 e 2013 (BRIC 2009, item 11; BRICS, 2012, item 48). No entanto, com a $1^{\text {a }}$ Reunião dos Ministros da Educação do BRICS em Paris, em novembro de 2013, no contexto da $37^{\mathrm{a}}$ sessão da Conferência Geral da UNESCO (que constituiu a base do BRICS), conforme Relatório Building Education for the Future, a cooperação educacional intra-BRICS ganhou impulso. Enquanto a Declaração de Fortaleza (BRICS, 2014, item 56) pela primeira vez enfatiza a "importância estratégica da educação para o desenvolvimento sustentável e o crescimento econômico inclusivo", uma agenda de educação comum foi 
estabelecida em 2015 por intermédio da $2^{\mathrm{a}}$ e $3^{\mathrm{a}}$ Reuniões dos Ministros da Educação do BRICS e em uma outra Reunião do Grupo de Trabalho sobre Educação do BRICS (BRICS 2015b, c, d). Essa agenda foi inicialmente enquadrada nos termos da hegemônica "Educação para Todos" e dos "Objetivos de Desenvolvimento do Milênio" (BRICS 2014, item 56), substituída desde 2015 pelos "Objetivos de Desenvolvimento Sustentável”, ou seja, o Objetivo 4 relacionado à educação com seus objetivos de "educação de qualidade inclusiva e equitativa " e "oportunidades de aprendizagem ao longo da vida para todos" (BRICS, 2016b; 2017a).

O discurso educativo do BRICS ecoa as ambiguidades inerentes ao discurso comum às cúpulas. Primeiro, ao longo de 2015-2017, pode-se afirmar que a repetitiva referência às ideias gerais de cooperação Sul-Sul de "interesse mútuo", "compreensão mútua" e "interesses comuns" (no total de 7 menções, ver BRICS, 2015b, d; BRICS 2016b BRICS 2017a), enquanto o uso de "sinergias" existentes (BRICS 2015b, item 12) foi omitido do discurso. Em segundo lugar, em 2015, uma mudança discursiva poderia ser observada dentro do discurso educacional do BRICS. Durante esse ano, "compartilhamento" e "troca" de "melhores práticas" (BRICS 2015b, itens 3, 13) foi substituído por "implementação" de "melhores práticas internacionais" (BRICS 2015c, item 14; 2015d, item 11), enquanto as dimensões políticas neoliberais (anglocêntricas) de "benchmarking" e "excelência" tornaram-se discursivamente integradas em novembro de 2015 (BRICS, 2015d, itens 2, 13, 14). No entanto, enquanto a "partilha de melhores práticas" voltou a entrar no discurso em 2016 (substituindo "implementação" de "melhores práticas internacionais"), as ideias de "benchmarking" e "excelência" foram abandonadas (BRICS, 2015e; BRICS 2016b; BRICS, 2017a). Para David e Motala, permanecem inconclusivos o potencial do BRICS de fornecer “significados alternativos às noções de 'excelência' e 'classe mundial"” (2017, p. 525). No entanto, uma questão igualmente pertinente levantada pelos autores é a incompatibilidade entre cooperação solidária e concorrência. Especialmente se a cooperação educacional do BRICS servir para o fortalecimento do discurso a respeito do estabelecimento de "universidades de classe mundial" para competição no mercado global de educação superior. Alternativamente, fortalece a solidariedade se o BRICS foca em "preferências nacionais" e em "interesses e problemas comuns do grupo ao invés de classificação global (rankings)" (DAVID; MOTALA, 2017, p. 520).

O delineado discurso híbrido do BRICS fornece algumas limitadas respostas a essas questões. Embora "solidariedade" esteja ausente nos documentos relativos ao ensino do 
BRICS de 2015-2017, o "desenvolvimento de metodologias conjuntas para indicadores educacionais" por intermédio de "colaboração" na forma de "suporte técnico mútuo" serve para "apoiar a tomada de decisão nos Estados membros do BRICS" (BRICS 2015b, item 2; 2015c, item 7). Isso sugere que, em vez de desenvolver indicadores para fins competitivos, como no projeto neoliberal, busca-se o desenvolvimento coletivo: "cooperação nas relações sociais e trabalhistas para estabelecer cooperação social, política e cultural em larga escala e assegurar um nível qualitativamente novo de relações externas para o BRICS" (BRICS 2015c). Como explica Dilvo Ristoff, chefe da delegação brasileira nas reuniões do BRICS até 31 de agosto de 2016 (durante o governo Dilma Rousseff), a atmosfera nas reuniões dos representantes dos países componente do BRICS sempre foi muito cordial e produtiva. Os países parceiros reunidos no BRICS tratavam-se uns aos outros "como iguais, em busca de um projeto de interesse mútuo - um projeto de universidade que viesse a contribuir para o desenvolvimento de todos os países envolvidos" (RISTOFF, 2016a).

Ao mesmo tempo, de acordo com o discurso da educação global (mais recentemente o Objetivo ODS 4 - Objetivos de Desenvolvimento Sustentável, em relação à Educação - 4), o compromisso com as "oportunidades de aprendizagem permanente para todos" é uma constante na agenda educacional do BRICS (BRICS 2015b, c, d; BRICS 2016b; BRICS 2017a). Isso coincide com o objetivo de integrar as "metas relacionadas ao ODS 4 com os planos/programas de desenvolvimento do setor educacional em nível nacional e subnacional" (BRICS, 2017a, item 2). Em 2015, a educação era vista como um "investimento" para o “desenvolvimento de recursos humanos" (BRICS 2015d, item 17), e até mesmo a "educação pré-escolar" se instrumentalizou para o "desenvolvimento de habilidades e competências indispensáveis para atividades inovativas" (BRICS 2015c, item 8) - isto é, para o crescimento econômico. Essa estreita visão capitalista, no entanto, foi substituída pela associação da educação superior como uma contribuição não apenas ao "desenvolvimento de recursos humanos de alto nível e apoio intelectual" para o desenvolvimento econômico, mas também para o "desenvolvimento social” (BRICS, 2017a).

Isso sugere que o BRICS reafirma o papel da educação no/para o desenvolvimento para além dos fins econômicos, o que é ressaltado pelo objetivo geral da cooperação educacional do BRICS de promover "intercâmbios culturais" via "intercâmbios de pessoas para pessoas" (BRICS, 2017a). Embora a promoção do "contato de pessoa a pessoa no BRICS" tenha entrado no discurso em 2012 (BRICS, 2012, item 4), isto só se materializou a partir de 2016, entre outros modos, na forma de um festival de cinema, um torneio de futebol 
sub-17 e uma cúpula de jovens (BRICS, 2016c; BRICS 2017b, itens 63 e 66), transcendendo assim as meras relações intergovernamentais/inter-estados. Em 2017, essa dimensão transnacional foi declarada como sendo "o terceiro pilar da cooperação do BRICS" ${ }^{10}$ para "cultivar valores comuns com base na diversidade e no compartilhamento" (BRICS, 2017b, item 60).

A cooperação educacional está agora integrada neste "terceiro pilar" (BRICS, 2017b, Anexo 1) e iniciativas concretas incluem: a Universidade em Rede do BRICS (BRICS NU) e a Liga Universitária BRICS, “Cooperação cultural através da educação linguística e do multilinguismo", "Racionalização a cooperação entre think tanks educacionais e pesquisadores da educação", “Acampamentos de inverno/verão para jovens”, bolsas de estudo e defesa de "políticas globais de educação que levem em conta as preocupações e prioridades comuns dos Estados membros do BRICS" (BRICS, 2017a). Em termos de política, isso foi categorizado como: Educação Superior, Educação Profissional Técnica e Treinamento, Educação geral e Estratégia de Políticas Educacionais (BRICS, 2015d). No entanto, "a educação superior e a pesquisa são prioridades" (BRICS 2015b, item 8), em que a Liga Universitária BRICS (BRICS 2015b, item 9) e a Universidade em Rede do BRICS foram criados para promover "profissionalização de acadêmicos" (BRICS, 2017a, item 3) por intermédio da mobilidade acadêmica e do estabelecimento de redes de pesquisa, entre outros, via programas de mestrado e doutorado (SMAGINA, 2016) "em áreas de interesse mútuo" (BRICS 2015b, item 8): energia, ciência da computação e segurança da informação, Estudos do BRICS, ecologia e mudança climática, recursos hídricos e tratamento de poluição e economia (BRICS 2015e).

Considerado até agora o "projeto mais ambicioso do BRICS no âmbito da educação e da pesquisa" (SMAGINA, 2016, p. 144), a Universidade em Rede do BRICS não é uma instituição supranacional, mas uma estrutura internacional regida por Comitês de Coordenação Nacional criados em cada estado membro do BRICS por seus Ministérios da Educação e financiados pelas universidades participantes (BRICS 2015e, Artigo 13). Enquanto esta Rede Universitária em sua etapa de fundação integra um máximo de 12 universidades públicas de cada membro do BRICS - em abril de 2016, um total de 45 universidades se comprometeram a participar do projeto (SMAGINA, 2016, p. 150).

${ }^{10}$ Os outros dois pilares são "Cooperação Política e de Segurança" e "Cooperação Econômica”. (BRICS, 2017b, Annex 1)*. 
Há outras iniciativas que integram a cooperação educacional do BRICS, como o Programa-Quadro Científico, Tecnológico e de Inovação do BRICS para projetos conjuntos de pesquisa entre parceiros de pelo menos três membros do BRICS, também aberto às instituições privadas sem fins lucrativos (BRICS 2016a). Ristoff, em comunicação eletrônica pessoal com os autores, revela que a Rússia propôs a Universidade em Rede do BRICS e a que a China contribuiu com a ideia de uma Liga Universitária BRICS, com o entendimento de que ambas as iniciativas "são projetos que se complementam" (RISTOFF, 2016a). Isso ocorre "de acordo com as diretrizes, normas e regulamentos nacionais de cada um dos países do BRICS” (BRICS 2015e, artigo 11). Por exemplo, no que diz respeito ao Brasil, a criação da Universidade em Rede do BRICS e da Liga Universitária BRICS está alinhada com outros esforços de internacionalização considerados no "Plano de Desenvolvimento da Universidade do Brasil (PDU), ainda em construção" (RISTOFF, 2016a) e no Plano Nacional de Educação (PNE) 2014-2024. Como Ristoff mostra em uma contribuição para um boletim publicado pela Ural Federal University (Rússia),

Iniciativas como a recém criada Universidade em Rede do BRICS e a Liga Universitária BRICS mostraram-se perfeitamente alinhadas com a estratégia 14.9 do PNE brasileiro. Também estão alinhadas com as estratégias 14.10 e 14.13 da mesma meta 14, que afirmam: (a) promover o intercâmbio científico e tecnológico, nacional e internacional,entre as instituições de ensino, pesquisa e extensão; (b) aumentar qualitativa e quantitativamente o desempenho científico e tecnológico do país e a competitividade internacional da pesquisa brasileira,ampliando a cooperação científica com empresas, instituições de educação superior (IES) e demais instituições científicas e tecnológicas $(I C T s)^{11}$.

Embora seja cedo para chegar a uma conclusão, ainda que provisória, pode-se dizer que, apesar das ambiguidades e contradições potenciais, percebemos que a cooperação educacional do BRICS contribui para a construção de uma estrutura de contra dependência. Isto pois, não obstante, os estados membros individuais implementam políticas de integração ao mercado capitalista global de educação superior, como a China e a Índia, que têm sido os "principais países emissores" de estudantes internacionais para "grandes universidades de língua inglesa" (ALTBACH; BASSETT, 2014, p. 2), a cooperação no BRICS procura para construir e gerar "sinergias" (BRICS, 2012; 2015a, b). Como as sinergias são geradas por

${ }^{11}$ Além disso, "o que torna essas metas e estratégias particularmente significativas é que, com sua inclusão no Plano Nacional de Educação de dez anos, levaram os elaboradores de políticas educacionais brasileiras de uma fase de desejo para um nível em que planos, programas e projetos de internacionalização das universidades brasileiras tornaram-se uma exigência legal, que visa promover uma missão considerada estratégica para a construção de uma nação avançada nas ciências e nas artes, soberana, democrática, inclusiva e a serviço da emancipação social" (Ristoff, 2016b: 17). 
meio de relações de cooperação, como na Universidade em Rede do BRICS, a pesquisa destas exige uma metodologia relacional, em vez de comparação entre os estudos individuais de cada país.

\section{Conclusão}

Este artigo desenvolveu-se tendo por eixo a questão de saber se as relações de educação Sul-Sul representam simplesmente "transferência de melhores práticas" ou se fornecem uma alternativa à mercantilização e à privatização da educação e se é capaz de construir uma contra-estrutura ao projeto político de governança global neoliberal da educação. Apesar do predomínio de um viés centrado no Norte Global ou na eurocêntrica literatura anglófona sobre o tema, também identificamos um corpo de literatura que ressalta que os princípios Sul-Sul de solidariedade, benefícios mútuos e esforços de autoconfiança são muito praticados.

No entanto, alegar que esses projetos culminariam em um desafio estrutural aos interesses do capitalismo global seria exagero. Grande parte da literatura revisada confirma a instrumentalização e a cooptação da cooperação Sul-Sul como "colaboração triangular", como iniciativas voltadas para o Norte que procuram ativamente integrar os sistemas de educação e projetos de cooperação do Sul aos circuitos globais de educação neoliberal. A revisão da literatura e nossos estudos de caso, no entanto, revelam igualmente que há mais na imagem do que os primeiros olhares poderiam perceber. Ao desenvolver algumas proposições para estudos futuros, esta seção final chama a atenção para projetos e relações de educação Sul-Sul que têm sido ou marginalizados na literatura existente ou são completamente invisibilizados pelos discursos dominantes.

Primeiro, no que diz respeito às relações bilaterais, a cooperação Sul-Sul da Índia em "educação e treinamento técnico e profissional" com parceiros como Afeganistão, Indonésia, Maldivas, Mongólia, Namíbia, Senegal, África do Sul, Vietnã e Zimbábue (TILAK, 2016, p. 312) recebe pouca atenção pelas pesquisas, assim como as relações de cooperação em educação da China com os parceiros do Sul não-Africano. Igualmente, também ausente nas discussões acadêmicas, estão a cooperação educacional venezuelana de grande escala, iniciada nos anos 2000, com quase todos os estados africanos (esboçada em alguma literatura latino-americana, por exemplo em Lucena Molero, 2013), e a cooperação Vietnã-Laos e 
Vietnã-Camboja em "educação e treinamento e desenvolvimento de recursos humanos" (PEOPLE'S ARMY NEWSPAPER, 2016).

Em segundo lugar, no que diz respeito às formações regionais, enquanto a Associação de Nações do Sudeste Asiático (Association of Southeast Asian Nations; ANSEA/ASEAN) geralmente recebe considerável atenção acadêmica, os objetivos educacionais da ASEAN de construir uma "identidade ASEAN enraizada na amizade e cooperação" e "promover cooperação e solidariedade entre acadêmicos e pesquisadores nos países membros da ASEAN" (CHAO, 2016, p. 131, 132), empiricamente, permaneceram inexplorados.

O mesmo parece ser verdade sobre a Universidade Pan-Africana patrocinada pela União Africana, em relação a qual Lane \& Kinser (2013, p. 110) ressaltaram sua intenção de promover a "emancipação e libertação africana" e "desafiar a cidadela dos paradigmas eurocêntricos [...] e as epistemologias ocidentais do conhecimento" (NABUDERE, 2003, p. 2). Da mesma forma que o Fórum de Desenvolvimento das Ilhas do Pacífico como potencial esquema para a cooperação educacional Sul-Sul (FOX, 2014) também passou, em grande parte, despercebido.

Terceiro, em relação à cooperação multilateral global Sul-Sul, as lacunas de pesquisa persistem em relação ao fórum IBAS (India-Brasil-África do Sul), que segundo Tilak “enfatiza que a educação é vital para o desenvolvimento" (2016, p. 312); e as Cúpulas Trienais África-América do Sul (ASA) entre os Estados membros da União Africana e a União de Nações Sul-Americanas, UNASUL, cuja agenda de educação busca, entre outros objetivos, "fomentar redes de instituições de educação superior", incluindo a Universidade Pan-Africana "para expandir o acesso à educação superior, especialmente, para grupos vulneráveis" (ASA, 2013).

Estudos futuros, como este artigo sugere, precisam ser realizados a partir da (e pela) perspectiva do Sul global para recuperar a ideia de cooperação Sul-Sul como possibilidade de neutralização de uma suposta cooperação "triangular/Sul-Sul”. Isto é, deve-se "descentralizar o estrangulamento hegemônico da ordem epistemológica eurocêntrica - construindo saberes mais fortalecedores para o Sul e formas simétricas de internacionalização" (ZELEZA, 2012, p. 5).

\section{REFERÊNCIAS}

ABDENUR, A. E. Emerging powers as normative agents: Brazil and China within the UN development system. Third World Quarterly, v. 35, n. 10, p. 1876-1893, 2014. 
ALTBACH, P. G.; BASSETT, R. M. Nix the BRICS - at least for the higher education debate. International Higher Education, n. 77 (Fall 2013), p. 2-5, 2014.

ALTBACH, P. G.; REISBERG, L.; YUDKEVICH, M.; ANDROUSHCHAK, G.; KUZMINOV, Y. (Eds.). The global future of higher education \& the academic profession: The BRICs and the United States. Basingstoke, England: Palgrave Macmillan, 2013.

ANGOSTO-FERRÁNDEZ, L. F. "Ordering Discontent: Domestic and International Dynamics of the Bolivarian Revolution.” In: ANGOSTO-FERRÁNDEZ, L. F. (ed.) Democracy, Revolution, and Geopolitics in Latin America: Venezuela and the International Politics of Discontent. London: Routledge, 2014. p. 177-194.

ASA. Inputs of Working Groups: Africa - South America Implementation Plan 2013-2016. Malabo, 20-22 February, 2013.

AZEVEDO, M. L. N. The Bologna Process and higher education in Mercosur: regionalization or Europeanization? International Journal of Lifelong Education, v. 33, n. 2, p. 411-427, 2014.

AZEVEDO, M. L. N. Internacionalização ou transnacionalização da educação superior: entre a formação de um campo social global e um mercado de ensino mundializado. Crítica Educativa, v. 1, n. 1, p. 56-79, 2015a.

AZEVEDO, M. L. N. Higher education and international organizations: Cold War, commodification, and the global field of power. In: TULESKI, S. (ed.) Liberation Psychology in Brazil. New York: Nova, 2015b. p. 13-39.

BOUGHTON, B.; DURNAN, D. Cuba's "Yes, I can" mass adult literacy campaign model in Timor-Leste and aboriginal Australia: a comparative study. Int. Rev. Educ., v. 60, n. 4, p. 559-580, 2014.

BOUGHTON, B.; DURNAN, D. Popular education pedagogy and south-south solidarity. An Asia-Pacific perspective. In: KOTZE, A. V.; WALTERS, S. (Eds.) Forging Solidarity. Popular Education at Work. Rotterdam: Sense, 2017. p. 39-48.

BRIC. Joint Statement of the BRIC Countries' Leaders. Yekaterinburg, 16 June, 2009.

BRIC. Joint Statement. 2nd Summit of Heads of State and Government. Brasilia, 15 april, 2010.

BRICS. Sanya Declaration + Action Plan. Sanya, 14 april, 2011.

BRICS. Delhi Declaration + Action Plan. New Delhi, 29 march, 2012.

BRICS. eThekwini Declaration + Action Plan. Durban, 27 march, 2013.

BRICS. Fortaleza Declaration + Action Plan. Fortaleza, 15 july, 2014. 
BRICS. Ufa Declaration + Action Plan. Ufa, 9 july, 2015a.

BRICS. Brasilia Declaration. Declaration of the II Meeting of BRICS Ministers of Education. Brasilia, 2 march, $2015 b$.

BRICS. Conclusions. Meeting of the BRICS Working Group on Education. 25-26 june, 2015c.

BRICS. Moscow Declaration. Declaration of the III Meeting of BRICS Ministers of Education. Moscow, 18 november, 2015d.

BRICS. Memorandum of Understanding on Establishment of the BRICS Network University. Moscow, 18 november, 2015e.

BRICS. BRICS STI Framework Programme Coordinated call for BRICS multilateral projects - Pilot call, 2016a.

BRICS. New Delhi Declaration on Education. New Delhi, 30 september, 2016 b.

BRICS. Goa Declaration + Action Plan. Goa, 16 october, 2016c.

BRICS. Beijing Declaration of Education. Beijing, 5 july, 2017a.

BRICS. BRICS Leaders Xiamen Declaration + Action Plan. Xiamen, 4 september 2017b.

BUZAN, B.; HELD, D.; MCGREW, A. (1998) Realism vs cosmopolitanism. Review of International Studies, v. 24, n. 3, p. 387-398, 1998.

CAPORASO, J. A. Dependence, Dependency, and Power in the Global System: A Structural and Behavioral Analysis. International Organization, v. 32, n. 1, p. 13-43, 1978.

CARNOY, M.; LOYALKA, P.; DOBRYAKOVA, M.; DOSSANI, R.; FROUMIN, I.;

KUHNS, K.; TILAK, J.; WANG, R. University expansion in a changing global economy: Triumph of the BRICs? Stanford, CA: Stanford University Press, 2013.

CASTELLS, M. End of Millennium. 2. ed. Oxford: Blackwell, 2000.

CHAO, R. Y. Changing higher education discourse in the making of the ASEAN region. In: ROBERTSON, S. L.; OLDS, K.; DALE, R.; DANG, Q. A. (eds) Global Regionalisms and Higher Education: projects, processes, politics. Cheltenham: Edward Elgar, 2016. p. 124142.

CHATURVEDI, S. "Development Cooperation: Contours, Evolution and Scope." In: CHATURVEDI S.; FUES, T.; SIDIROPOULOS, E. (eds) Development Cooperation and Emerging Powers. London: Zed, 2012. p. 13-36.

CHENG, I-H.; CHAN, S-J. International Education Aid in Developing Asia: Policies and Practices. Dordrecht: Springer, 2015. 
CHISHOLM, L. "Introduction: Rhetoric, Realities, and Reasons." In: CHISHOLM, L.; STEINER-KHAMSI, G. (eds) South-South Cooperation in Education and Development. New York: Teachers College, 2009. p. 1-13

COOPER, A. F. The BRICS' New Development Bank: Shifting from material leverage to innovative capacity. Global Policy, v. 8, n. 3, p. 275-284, 2017.

DALE, R. Globalisation, knowledge economy and comparative education. Comparative Education, v. 41, n. 2, p. 117-149, 2005.

DAVID, S. A.; Motala, S. Can BRICS build ivory towers of excellence? Giving new meaning to world-class universities. Research in Comparative \& International Education, v. 12, n. 4, p. 512-528, 2017.

DICKEN, P. Global Shift. 6. ed. London: Guildford, 2011.

DOLOWITZ, D. P.; MARSH, D. Learning from abroad: the role of policy transfer in contemporary policy-making. Governance. International Journal of Policy and Administration, v. 13, n. 1, p. 5-23, 2000.

DOMÍnguEZ, J. L. To Make a World Safe for Revolution: Cuba's Foreign Policy. Cambridge, MA: Harvard University, 1989.

ERISMAN, M. Cuban Development Aid: South-South Diversification and Counterdependency Politics. In: ERISMAN, M.; KIRK, J. (eds) Cuban Foreign Policy Confronts a New International Order. London: Lynne Rienner, 1991. p. 139-165.

FAIRCLOUGH, N. Analysing Discourse. London Routledge, 2003.

FIDDIAN-QASMIYEH, E. South-South Educational Migration, Humanitarianism And Development. Views From The Caribbean, North Africa And The Middle East. Abingdon: Routledge, 2015.

FOX, C. Future directions for comparative education dialogue in the Asia-Pacific region. Asia Pacific Journal of Education, v. 34, n. 2, p. 212-227, 2014.

GOSOVIC, B. The resurgence of South-South cooperation. Third World Quarterly, v. 37, n. 4, p. 733-743, 2016.

HEYNEMAN, S. P. South-South Cooperation in Education and Development edited by Linda Chisholm and Gita Steiner-Khamsi. Comparative Education Review, v. 54, n. 3, p. 447449, 2010.

HICKLING-HUDSON, A.; CORONA GONZÁLEZ, J.; PRESTON, R. (Eds.). The Capacity to Share: A Study of Cuba's International Cooperation in Educational Development. Houndmills: Palgrave Macmillan, 2012. p. 13-34. 
HOPEWELL, K. The BRICS - merely a fable? Emerging power alliances in global trade governance. International Affairs, v. 93, n. 6, p. 1377-1396, 2017.

JULES, T. D.; MORAIS DE SÁ E SILVA, M. M. How Different Disciplines have Approached South-South Cooperation and Transfer. Society for International Education Journal, v. 5, n. 1, p. 45-64, 2008.

KING, K. China's Aid and Soft Power in Africa. The Case of Education and Training. Woodbridge: James Currey, 2013.

LANE, J. E.; KINSER, K. Cross-border higher education in Africa: collaboration and competition. In A.W. Wiseman \& C.C. Wolhuter (eds) The Development of Higher Education in Africa: Prospects and Challenges. London: Emerald, 2013. p. 99-126.

LECHINI, G. Reflexiones en torno a la cooperación Sur-Sur. In C. Morasso \& G. Pereyra Doval (eds) Argentina y Brasil: proyecciones internacionales, cooperación sur-sur e integración. Rosario: UNR, 2012. p. 14-25.

LUCENA MOLERO, H. La agenda África venezolana (2005-2012). Humania del Sur 8, n. 14, p. 135-154, 2013.

MUHR, T. Counter-hegemonic regionalism and higher education for all: Venezuela and the ALBA. Globalisation, Societies and Education, v. 8, n. 1, p. 39-57, 2010.

MUHR, T. South-South cooperation in education and development: the ¡Yo, Sí Puedo! literacy method. International Journal of Educational Development, v. 43, p. 126-133, 2015. DOI: 10.1016/j.ijedudev.2015.04.005.

MUHR, T. Beyond 'BRICS': ten theses on South-South cooperation in the 21 st century. Third World Quarterly, v. 37, n. 4, p. 630-648, 2016 a.

MUHR, T. Equity of access to higher education in the context of South-South cooperation in Latin America: a pluri-scalar approach. Higher Education, v. 72, n. 4, p. 557-571, 2016b.

NABUDERE, D. W. Towards the establishment of a Pan-African University: a strategic concept paper. African Journal of Political Science, v. 8, n. 1, p. 1-30, 2003.

NEWMAN, E.; ZALA, B. Rising powers and order contestation: disaggregating the normative from the representational. Third World Quarterly, 2017. DOI: 10.1080/01436597.2017.1392085.

NIU, C.; LIU, J. Positioning China's aid to educational development in Africa: past, present, and post-2015. In: YAMADA, S. (ed) Post-Education-for-All and Sustainable Development Paradigm: structural changes with diversifying actors and norms. Bingley: Emerald, 2016. p. 269-299.

NOWAK, M. Introduction to the International Human Rights Regime. Leiden/Boston: Brill Academic Publishers, 2003. 
NYE, J. S. Responding to my critics and concluding thoughts. In: PARMAR, I.; COX, M. (eds) Soft Power and US Foreign Policy. London: Routledge, 2010. p. 215-227.

OLEKSIYENKO, A.; YANG, R. Nix the BRICs? Competitive and collaborative forces in the ostensibly 'blocalized' higher education systems. Frontiers of Education in China, v. 10, n. 1, p. 1-6, 2015.

O’NEIL, J. Building better global economic BRICs. Global Economics Paper n. 66. New York: Goldman Sachs, 2001.

PEOPLE'S ARMY NEWSPAPER. Important political event for Vietnam-Laos and Vietnam-Cambodia relations, june 12, 2016.

PERROTTA, D. MERCOSUR, regulatory regionalism and contesting projects of higher education governance. In: ROBERTSON, S. L.; OLDS, K.; DALE, R.; DANG, Q. A. (eds). Global Regionalisms and Higher Education: Projects, Processes, Politics. Cheltenham: Edward Elgar, 2016. p. 228-252.

PHẠM, QUỲNH N. Y ROBBIE SHILLIAM. Meanings of Bandung. Postcolonial Orders and Decolonial Visions. London: Rowman \& Littlefield, 2016.

PILLAY, P.; PINHEIRO, R.; SCHWARTZMAN, S. Higher Education in the BRICS Countries: investigating the pact between higher education and society. Dordrecht: Springer, 2015.

RISTOFF, D. BRICS Rede de universidades. Personal digital communication, 17 September, 2016a.

RISTOFF, D. International cooperation in higher education: Trends and challenges. In: BRICS. BRICS Studies Centre Newsletter, 1(winter-spring), 2016b. p. 10-18.

ROBERTSON, S.; DALE, R. Researching education in a globalising era: beyond methodological nationalism, methodological statism, methodological educationism and spatial fetishism. In: RESNICK J. (ed.) The Production of Educational Knowledge in a Global Era Rotterdam: Sense Publishers, 2008. p. 19-32.

SMAGINA, I. The first forum of the BRICS Network University. BRICS Law Journal, v. 3, n. 1, p. 144-151, 2016.

SÁ E SILVA, M. M. South-South cooperation: past and present. Conceptualization and practice. In: CHISHOLM, L.; STEINER-KHAMSI, G. (eds.) South-South Cooperation in Education and Development. New York, Teachers College Press, 2009. p. 39-59.

STEELE, J. Yo, Sí Puedo: South-South educational collaboration in practice. Society for International Education Journal, v. 5, n. 1, p. 29-43, 2008.

STEINER-KHAMSI, G. International knowledge banks and the production of educational crises. EERJ Roundtable. eur. educ. res. j., v. 6, n. 3, p. 285-292, 2007. 
STEINER-KHAMSI, G. Understanding policy borrowing and lending. Building comparative policy studies. In: STEINER-KHAMSI, G.; WALDOW, F. (eds) World Yearbook of Education 2012: policy borrowing and lending in education. London: Routledge, 2012. p. 317.

TILAK, J. B. G. South-South cooperation: India's programme of development assistance nature, size and functioning. In: YAMADA S. (ed) Post-Education-for-All and Sustainable Development Paradigm: structural changes with diversifying actors and norms. Bingley: Emerald, 2016. p. 301-326.

TÜNNERMANN BERNHEIM, C. Central America: Quality assurance and accreditation. In: LÓPEZ SEGRERA, F.; BROCK, C.; DIAS SOBRINHO, J. (Eds.), Higher education in Latin America and the Caribbean 2008. Caracas: UNESCO/IESALC, 2009. p. 49-68.

UNESCO. BRICS. Building Education for the Future. Priorities for National Development and International Cooperation. Paris: UNESCO, 2014.

UNITED NATIONS. Declaration on the Right to Development. United Nations General Assembly, A/RES/41/128, 97th Plenary Meeting, 4 december, 1986.

WERNER, M. "Contesting Power/Knowledge in Economic Geography: Learning from Latin America and the Caribbean." In: BARNES, T. J.; PECK, J.; SHEPPARD, E. (eds) The Wiley-Blackwell Companion to Economic Geography. Chichester: Blackwell Publishing, 2012. p. 132-145.

YANIK, L.K. The politics of educational exchange: turkish education in Eurasia. EuropeAsia Studies, v. 56, n. 2, p. 293-307, 2004.

ZELEZA, P. T. Internationalisation in higher education: Opportunities and challenges for the knowledge project in the Global South. SARUA Leadership Dialogue Series, v. 4, n. 2, p. 4$27,2012$.

\section{Como referenciar este artigo}

MUHR, Thomas.; AZEVEDO, Mário Luiz Neves de. Relações Sul-Sul em Educação: o programa ¡Yo, Sí Puedo! e a cooperação em educação do BRICS em foco. Revista IberoAmericana de Estudos em Educação, Araraquara, v. 14, n. 1, p. 2-30, jan./mar., 2019. EISSN: 1982-5587. DOI: 10.21723/riaee.v14i1.11730

Submissão: $10 / 09 / 2018$

Revisões requeridas: $23 / 11 / 2018$

Aprovação final: 26/11/2018 